\title{
Pentoxifylline Explores New Horizons in Treatment of Hashimoto Thyroiditis
}

\section{Arsalan Azimi}

Doctor of Medicine, Shiraz University of Medical Sciences, Shiraz, Iran

*Corresponding author: Arsalan Azimi, Doctor of Medicine, Shiraz University of Medical Sciences, Shiraz, Iran, Tel: +989171066597; E-mail: arsalan.azimi@gmail.com Received date: February 01, 2016; Accepted date: February 20, 2016; Published date: February 25, 2016

Copyright: () 2016 Azimi A. This is an open-access article distributed under the terms of the Creative Commons Attribution License, which permits unrestricted use, distribution and reproduction in any medium, provided the original author and source are credited.

\begin{abstract}
Hashimoto Thyroiditis is an autoimmune disease and the most common cause of hypothyroidism in developed countries. As the disease initiates unusual thyroidal antigens are exposed to the immune system. The immune system sensitizes to those antigens and creates a cell mediated autoimmune response against thyroid gland. Inflammatory cells infiltrate within thyroid follicles and destruct the follicles by inflicting oxidative stress and inducing apoptosis. The inflammatory process also reduces sensitivity of thyrocytes to Thyroid Stimulating Hormone (TSH). As the disease progresses and the follicles degrade, fibrotic tissue replaces the follicles until the whole gland becomes fibrotic. Pentoxiflline could inhibit autoimmune destruction of thyrocytes, suppress cell mediated immune response against thyroid, decrease oxidative damage to thyrocytes, increase sensitivity of thyrocytes to TSH and hinder fibrotic degeneration of thyroid. Thereby PTX could cure HT and alleviate symptoms of hypothyroidism.
\end{abstract}

\section{Introduction}

Hashimoto thyroiditis (HT) is an organ specific auto-immune disease characterized by presence of auto-antibodies against thyroid antigens, infiltration of leukocytes within the thyroid follicles and destruction of thyrocytes, with a male/female ratio of 1:10-1:20. [1] In iodine sufficient parts of the world, HT is the most common cause of hypothyroidism [2]. Although previous studies had estimated annual worldwide incidence of Hashimoto thyroiditis as 0.3-1.5 cases per 1000 persons, a newer study has revealed that HT is more frequent than expected and the prevalence of euthyroid/hypothyroid patients with HT appears to be even more than 5\% in general population [3-5] Patients often remain asymptomatic for many years and they develop clinical symptoms of hypothyroidism only after advanced destruction of thyroid follicles [1].

Expression of thyroid-specific auto-antibodies against thyroidal antigens leads to infiltration of immune cells in thyroid follicles. Destruction of thyroid follicles by these immune cells is the main mechanism of pathogenesis in HT [6]. Cellular immunity plays the major role in destruction of thyrocytes [7]. HT is a Th1 mediated autoimmune disease and cytotoxic immune cells destroy thyrocytes by induction of apoptosis [6].

Although HT is a frequent autoimmune disease and the leading cause of hypothyroidism in developed countries, the initial process which triggers the disease sequel is not completely understood [8]. Both genetic and environmental factors play roles in the etiology of the disease [9]. Environmental factors including excessive iodine intake, selenium deficiency, pollutants such as tobacco smoke, some infectious diseases, and certain drugs could increase the risk of initiation of HT, primarily in genetically predisposed people [10]. Genetic development of HT is related to genes that over-express Interferon gamma (IFN- $\gamma$ ) [11]. As the disease initiates, thyrocytes enter a cytostatic state followed by progressive destruction and impaired regeneration of thyroid gland which could result in hypothyroidism [12].
Oxidative stress also plays an important role in pathogenesis of the disease. Physiologically, synthesis of thyroid hormones inflicts oxidative stress on thyrocytes [13]. Alteration of cellular defense against oxidative stress results in oxidative damage to thyrocytes, initiating aberrant cell apoptosis and necrosis of the cells, which exposes unusual epitopes to immune system $[14,15]$. The theory is validated as some antioxidants could alleviate pathogenesis of the disease. For instance, 3 month supplementation with Selenium, an antioxidant, is followed by a significant decrease in serum levels of anti-TPO in patients with HT [16-20]. Selenium is a trace element with multiple tasks within the body and it is also a major component of seleno-enzymes [20], which act in metabolism of thyroid hormones and cellular defense against oxidative stress [18]. Selenium supplementation reinforces intra-thyroidal seleno-enzymes, boosts cellular defense against oxidative damage, modulates production of reactive oxygen species and regulates metabolism of thyroid hormones [18].

Pentoxifylline (PTX) is a methylxanthine derivative with chemical name of 1-5-oxohexyl-3,7-dimethylxanthine [21]. It is shown to reduce ischemia-reperfusion induced damage, inactivate superoxide anions, improve endothelial function and vasodilatation, increase erythrocyte flexibility, attenuate inflammatory reactions, reduce viscosity of blood and inhibit platelet aggregation [21,22]. FDA has approved the agent to treat symptoms of intermittent claudication resulting from peripheral arterial disease [23]. It has also been used to treat Glomerular proteinuric nephropathy, Multi-infarct dementia, Peyronie's disease, Sarcoidosis, Peripheral neuropathy, Sickle cell disease, Alcoholic and non-alcoholic steato-hepatitis, Endometriosis and Radiation-induced fibrosis [24-34].

Gathering the current knowledge together, herein it is hypothesized that PTX can be used as a treatment regime for HT with the goal of remission of the disease but not palliation of disease symptoms. 


\section{Hypothesis}

It is hypothesized that PTX may alleviate autoimmune destruction of thyroid gland, it may ameliorates symptoms of HT and it is possible to exert curative effects on HT. Herein, we have gathered the current knowledge together to conclude a uniform pathophysiological mechanism for HT. Thus, based upon the mentioned mechanism involved in the disease, we have suggested a medication (Pentoxifylline) that can alter the pathologic state of the disease in order to prevent both the development and progression of its process. In addition to the main hypothesis, several other relevant hypotheses are also implied.

PTX may decelerate cell-mediated auto immune destruction of thyrocytes during HT.

PTX could increase sensitivity of thyrocytes to TSH and it could facilitate regeneration and redevelopment of thyroid tissue in response to TSH.

\section{PTX could decrease switching of Th17 cells toward Th1cells.}

PTX could decelerate infiltration of leukocytes through thyroid follicles during HT.

PTX could ameliorate and attenuate adverse effects oxidative stress in initiation process and during the course of HT.

PTX could ameliorate attenuated effects of TSH on thyrocytes, during HT.

PTX could decrease and/or postpone fibrosis of thyroid gland during Hashimoto thyroiditis [35-39].

These hypotheses could be subjected to several clinical trials to evaluate the efficacy of this medication and compare it with current managements. To evaluate possible curative effects of the medication on the course of HT, PTX should be administered together with Levothyroxine and the patients should be followed by serum level of Anti-thyroid peroxidase antibody (Anti-TPO), Anti-thyroglobulin antibody (ATG) and TSH (Thyroid Stimulating Hormone). As it is expected by the hypothesis, a while after beginning of treatment with PTX, serum level of Anti-TPO and ATG would decrease and finally serum levels of Anti-TPO and ATG becomes near to normal. Then Levothyroxine should be tapered off; thereafter serum levels of TSH are expected to rise. This favors regeneration of the gland under influence of TSH. Finally upon the improvement of function of the gland, as serum levels of TSH normalizes again, PTX could be tapered off. After that, patients should be followed by TSH, Anti-TPO and ATG. Supplementation with Selenium all over this period could facilitate function and regeneration of thyroid gland. In order to evaluate the other minor hypotheses the patients could be followed with serial measurement of serum TSH, serial tissue biopsy and serial counting of Th17 cells.

\section{Evaluation of Hypothesis}

Increased vulnerability to oxidative stress, abnormal immune regulation, autoimmune destruction of thyroid gland, insensitivity to TSH and fibrosis of thyroid gland are found to be the major mechanisms of pathogenesis in HT.

For several reasons it is hypothesized that PTX has the potential to cure HT. PTX is an antioxidant and hypothetically it could improve cellular defense of thyrocytes against oxidative stress induced by synthesis of thyroid hormones or inflammation [13]. This may result in lesser rate of aberrant apoptosis of thyrocytes and lesser exposure of thyroid antigens to immune system. Hypothetically Less exposure to immune system could result in less significant immune response against thyroid antigens. In addition, there is a vicious cycle between autoimmune destruction of thyroid and the immune response against the gland. Pentoxifylline attenuates Th1-type immune reactions, so it can attenuate immune response against thyroid, which in turn decreases exposure of thyroid antigens to immune system [21]. As the rate of exposure decreases, the rate of anti-thyroid antibody formation diminishes. Hypothetically, PTX could also decrease infiltration of leukocytes within the thyroid gland. It also modulates many of the cytokines that are imbalanced during the course of the disease $[2,7,40-46]$. Thereby it is hypothesized that PTX may decelerate autoimmune destruction of thyroid. Resistance of thyrocytes against TSH is another complication of HT [12]. It is also hypothesized that PTX increases sensitivity of thyrocytes to TSH and accelerates regeneration of damaged gland. Finally PTX could decelerate rate of fibrosis of the thyroid which is the final fate of the gland in HT (Figure $1)$.

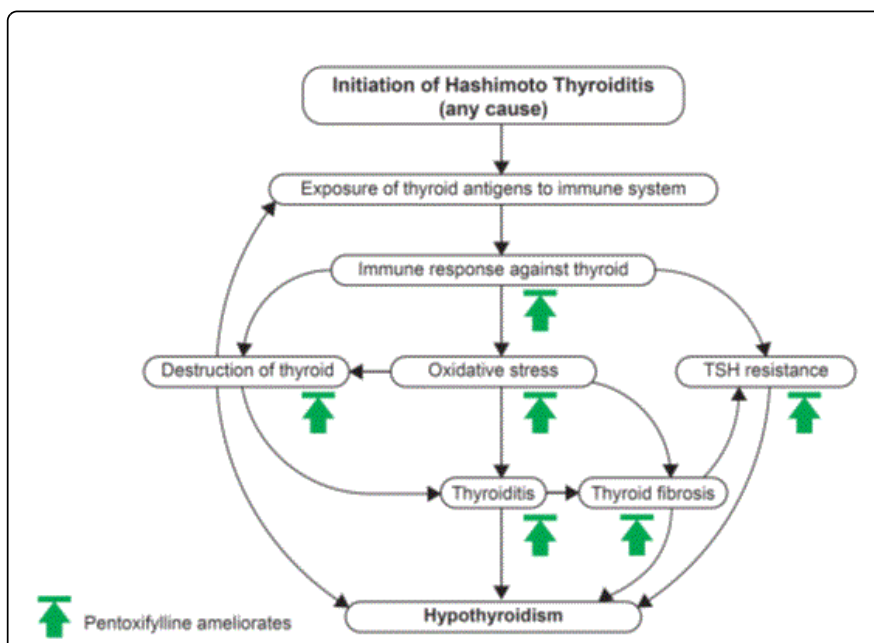

Figure 1: The initial processes thattu trigger the sequels of Hashimoto Thyroiditis (HT) are not completely understood, but as the disease initiates unusual thyroidal antigens are exposed to the immune system. The immune system sensitizes to those antigens and creates a cell mediated autoimmune response against thyroid gland. Inflammatory cells infiltrate within thyroid follicles and destruct the follicles by inflicting oxidative stress and inducing apoptosis. The inflammatory process also reduces sensitivity of thyrocytes to Thyroid Stimulating Hormone (TSH). As the disease progresses and the follicles degrade, fibrotic tissue replaces the follicles until the whole gland becomes fibrotic. Pentoxifline (PTX) could inhibit autoimmune destruction of thyrocytes, suppress cell mediated immune response against thyroid, decrease oxidative damage to thyrocytes, increase sensitivity of thyrocytes to TSH and hinder fibrotic degeneration of thyroid. Thereby PTX could cure HT and alleviate symptoms of hypothyroidism.

\section{PTX as an immunomodulator}

HT is a T-helper type $1(\mathrm{Th} 1)$ mediated autoimmune disease and in camparison with T-helper type 2 (Th2) mediated immune reactions; Th1 plays the major role in pathogenesis of the disease [6]. HT is 
initiated secondary to Th1/Th2 imbalance [6]. Pentoxifylline equilibrates Th1/Th2 imbalance and attenuates Th1-mediated immune reactions $[21,35]$. Thereby it is hypothesized that PTX could decelerate cell-mediated autoimmune destruction of thyrocytes in HT.

Lymphocytes infiltrated within the thyroid excrete higher levels of Tumor necrosis factor-alpha (TNF- $\alpha$ ), Interferon gamma (IFN- $\gamma$ ), interleukin $-1 \alpha(\mathrm{IL}-1 \alpha)$ and interleukin $-1 \beta$ (IL-1 $\beta)$, which stimulates the thyrocytes to express and excrete interleukin-6 (IL-6) [37-40]. TNF- $\alpha$, IFN- $\gamma$ and IL- $1 \beta$ are all major cytokines that induce apoptosis of thyrocytes via Tumor necrosis factor related apoptosis inducing Ligand (TRAIL)-induced-apoptosis-pathway [7]. PTX down-regulates expression of IFN- $\gamma$, IL-1 $\alpha$, IL-1 $\beta$, IL6, IL- 8 and TNF- $\alpha$, which are all up-regulated during HT [36-41]. In addition, PTX increases production and release of IL-10 which is shown to have curative effects on Hashimoto thyroiditis $[40,42]$. Human IL-10 interferes with cellular immunity in several fashions; not only it inhibits further expression of IFN- $\gamma$ by $\mathrm{T}$ cells, but it also down-regulates expression of other cellmediated-immunity related cytokines such as IL-1, IL-2,TNF- $\alpha$, IL-6 and IL-8 [2,42-46]. As mentioned before, cellular immunity plays the major role in destruction of thyrocytes in HT [7]. As PTX increases production and release of IL-10, and it also reduces production of IFN$\gamma$, IL-1 $\alpha$, IL-1 $\beta$, IL-2, IL6, IL-8 and TNF- $\alpha$ [2,40-46], it is hypothesized that PTX may decelerate cell-mediated auto immune destruction of thyrocytes during HT.

Over-expression of IFN- $\gamma$ plays an important role in the initiation of the disease [47]. It has been shown that exogenous administration of IFN- $\gamma$ induces an organ specific auto-immune thyroiditis with presence of anti-thyroglobulin and anti-microsomal antibodies [47]. In addition over-expression of IFN- $\gamma$ suppresses secretion of thyroid hormones from thyrocytes, since IFN- $\gamma$ inhibits functional and morphological response of human thyrocytes to Thyroid Stimulating Hormone (TSH) $[12,48]$. IFN- $\gamma$ Induces aberrant expression of MHCII antigens by thyrocytes [49]. Thyroid cell class II antigens participate in activation and amplification of $\mathrm{T}$ cell responses $[12,48]$. This process leads to further release of inflammatory cytokines including IFN- $\gamma$ and constitutes a vicious cycle [12,48]. Since PTX down regulates expression of IFN- $\gamma$, it is hypothesized that PTX unsettles the vicious cycle. As previously mentioned, IFN- $\gamma$ inhibits functional and morphological response of human thyrocytes to TSH $[12,48]$. Thus it is hypothesized that by down-regulating this cytokine, PTX could also increase sensitivity of thyrocytes to TSH and it could facilitate regeneration and redevelopment of thyroid tissue in response to TSH.

In animal models of autoimmune thyroiditis, Interleukin 12 (IL-12) has been demonstrated to be another initiator of Th-1 mediated response against thyrocytes [50]. Considering the issue that IL-12 induces further expression of IFN- $\gamma$, IL-12 can be the primary initiator of the disease process [50,51]. PTX also suppresses IL-12 inducted expression of IFN- $\gamma$ [51]. Thereby it is hypothesized that PTX counteracts the role of IL-12 in initiation and/or progression of the disease.

Th17 cells have been recently identified as a distinct $\mathrm{T}$ helper cell lineage and found to play important roles in inflammation and autoimmune diseases. It is shown that intra-thyroid infiltration of Th17 cells is significantly increased in the course of HT [52]. Generation of Th17 cells in humans requires IL-1 $\beta$ and IL- 6 with IL-2 as a survival factor $[53,54]$. In presence of IL-12, Th17 cells also express and secrete IFN- $\gamma$ [55-57]. In addition IL-12, shifts Th17 cells toward switching intoTh1 cells [58]. As previously mentioned, PTX down regulates IL- $1 \beta$, IL-6 and IL-2, so it is hypothesized that PTX alters generation and survival of Th17-cells. Furthermore, PTX inhibits production of IL-12 [59]. Therefore it is hypothesized that PTX could decrease switching of Th17 cells toward Th1cells, which are considered to play an important role in the pathogenesis of HT.

PTX also inhibits expression of Inter-Cellular Adhesion Molecle-1 (ICAM-1) on surface of stimulated mononuclear cells, which impairs their migration and infiltration $[60,61]$. Thereby it is hypothesized that PTX could decelerate infiltration of leukocytes through thyroid follicles.

\section{PTX as an antioxidant}

Previous studies have revealed that Selenium supplementation in patients with HT is followed by a significant decrease in anti-TPO levels [18-20]. Reinforcement of thyroid seleno-enzymes by Selenium is followed by modulation of oxidative stress and regulation of apoptosis [18-20]. It is hypothesized that by modulation of oxidative stress and apoptosis, unusual thyroidal epitopes are not formed and the immune system is no longer exposed to these aberrant self-antigens and as a result, formation of auto-antibodies is regressed. Hypothetically, this exposure could play an important role in initiation of autoimmune thyroiditis, thus using antioxidants which augment cellular defense against oxidative stress, could attenuate the destruction of thyrocytes. It is hypothesized that PTX could do so, since it is an anti-oxidant agent. 8-oxopentoxifylline, one of Pentoxifylline metabolites, is a potent antioxidant and free radical scavenger, which alleviates oxidative damage and strengthens cellular defense against oxidative stress [21]. Thereby it is hypothesized that PTX ameliorates and attenuates adverse effects oxidative stress in initiation process and during the course of HT.

\section{PTX as a TSH sensitizer}

It is also hypothesized that PTX could improve the effects of TSH on thyrocytes. Two main mechanisms are postulated. As previously mentioned, IFN- $\gamma$ inhibits functional and morphological response of human thyrocytes to TSH $[12,48]$. As previously mentioned, PTX down-regulates expression of IFN- $\gamma$. Thereby it is hypothesized that PTX could reduce the resistance of thyrocytes to TSH. On the other hand, as it is well known, classical human TSH signal transduction pathway includes cAMP as a secondary messenger. As a non-selective phosphodiesterase inhibitor, Pentoxifylline increases the amount of intracellular cAMP [62]. The same as TSH, FSH signal transduction highly depends on amounts of intracellular cAMP and it is shown that PTX boosts and improves the effects of FSH on male germinal cells [20]. As PTX increases the sensitivity to FSH, considering the issue that TSH and FSH are structurally similar to each other, it is hypothesized that PTX may do the same about TSH and thyrocytes. Indeed, it is hypothesized that PTX could ameliorate attenuated effects of TSH on thyrocytes, during HT.

\section{PTX as an anti-fibrotic agent}

As the disease progresses and the follicles degrade, fibrotic tissue replaces thyroid follicles and the disease process continues until the whole gland becomes fibrotic [63-67]. TGF- $\beta$ is a growth factor essential for tissue repair and also the main cause of tissue fibrosis [64]. Expression of TGF- $\beta$ is up regulated by IL- $1 \beta$ [66]. PTX down regulates expression of both IL- $1 \beta$ and TGF- $\beta$ and it is shown to decrease collagen synthesis and fibrosis of human peritoneum 
Page 4 of 6

$[40,41,65]$. Thus it is hypothesized that PTX could decrease fibrosis of thyroid gland during Hashimoto thyroiditis.

\section{Discussion}

HT is the most common cause of hypothyroidism in iodine sufficient parts of the world and it is routinely treated by replacement of thyroid hormones, most commonly Levothyroxine [2,5]. Current treatment is not a remission but only symptomatic, therapy. Prescription of the drug is not as simple as it may seem [68]. Different individuals may need different amounts of hormone replacement, and even one individual may not always require invariable amounts of the drug, because the need for amount of hormonal replacement depends on individuals' metabolic, physical and mental status [68]. In addition as the disease has a progressive course in most of the cases, so the demand for hormonal replacement increases as the thyroid function deteriorates [69-72]. Conversely as the patients with hypothyroidism become older, their demand for hormone replacement decreases and older individuals are at higher risk for overtreatment and iatrogenic thyrotoxicosis and over-replacement with levothyroxine could complicate the patients with osteoporosis and adverse cardiac events, especially atrial fibrillation [69-72]. Furthermore, the same doses of Levothyroxin manufactured by different incorporations do not necessarily result in similar responses in an individual [73]. These all further complicates adjustment of dose of the drug. Many of HT patients need the drug lifelong as their disease does not remit spontaneously [71]. Although Levothyroxine is a relatively available and inexpensive drug, since it is needed for a long period of time, the total cost of medication per patient would be significantly high [71]. In addition HT patients and TSH levels should be screened every 6-12 months, which further increases the total cost of treatment of the disease $[71,73]$. Considering the increased risk of papillary carcinoma of thyroid in persistence of HT [1] beside difficulties in dose adjustment of Levothyroxine, possible complications of over-treatment and significant total costs expended upon this symptomatic therapy, it is not irrational to think of an alternative treatment to cure the disease, but not palliation of its symptoms.

Here it is hypothesized that PTX could be an alternative therapy for HT. Although in comparison with Levothyroxine, PTX is a relatively expensive and less available drug, but it has tolerable adverse effects and it is a relatively safe drug $[74,75]$.Thereby as PTX has the potential to become an alternative in the treatment of HT and it is not needed to be prescribed lifelong, it is not irrational to put the hypothesis in a trial.

\section{Conclusion}

All clues together, PTX is an anti-inflammatory/anti-oxidant agent and it may reduce inflammation and aberrant apoptosis of thyroid epithelial cells. It may reduce exposure of intra cellular/follicular components to immune system and decrease infiltration of leukocytes within thyroid follicles. It may ameliorate decreased responsiveness of throcytes to TSH. PTX may accelerate regeneration of damaged thyrocytes as it suppresses IFN- $\gamma$ and up-regulates production of IL-10 and it also inhibits fibrosis of the gland. All in all PTX may have curative effects on HT and may have the potential to become an alternative treatment. Evaluation of the issue with clinical researches and cohort large studies are necessarily needed to validate/invalidate the hypothesis.

\section{References}

1. Singh B, Shaha AR, Trivedi H, Carew JF, Poluri A, et al. (1999) Coexistent Hashimoto's thyroiditis with papillary thyroid carcinoma: impact on presentation, management, and outcome. Surgery 126: 1070-1076.

2. Fava A, Oliverio R, Giuliano S, Parlato G, Michniewicz A, et al. (2009) Clinical evolution of autoimmune thyroiditis in children and adolescents. Thyroid 19: 361-367.

3. Vanderpump MP, French JM, Appleton D, Tunbridge WM, KendallTaylor P (1998) The prevalence of hyperprolactinaemia and association with markers of autoimmune thyroid disease in survivors of the Whickham Survey cohort. Clin Endocrinol (Oxf) 48: 39-44.

4. Vanderpump MP, Tunbridge WM, French JM, Appleton D, Bates D, et al. (1995) The incidence of thyroid disorders in the community: a twentyyear follow-up of the Whickham Survey. Clin Endocrinol (Oxf) 43: 55-68.

5. Staii A, Mirocha S, Todorova-Koteva K, Glinberg S, Jaume JC (2010) Hashimoto thyroiditis is more frequent than expected when diagnosed by cytology which uncovers a pre-clinical state. Thyroid Res 3: 11.

6. Bretz JD, Baker JR (2001) Apoptosis and autoimmune thyroid disease: following a TRAIL to thyroid destruction? Clinical Endocrinology 55: $1-11$

7. Weetman AP (2004) Cellular immune responses in autoimmune thyroid disease. Clin Endocrinol (Oxf) 61: 405-413.

8. Hollowell JG, Staehling NW, Flanders WD, Hannon WH, Gunter EW, et al. (2002) Serum TSH, T(4), and thyroid antibodies in the United States population (1988 to 1994): National Health and Nutrition Examination Survey (NHANES III). J Clin Endocrinol Metab 87: 489-499.

9. Brix TH, Hegedüs L (2012) Twin studies as a model for exploring the aetiology of autoimmune thyroid disease. Clin Endocrinol (Oxf) 76: 457-464.

10. Duntas LH (2008) Environmental factors and autoimmune thyroiditis. Nat Clin Pract Endocrinol Metab 4: 454-460.

11. Rekha PL, Ishaq M, Valluri V (2006) A Differential Association of Interferon-? High-Producing Allele T and Low-Producing Allele A (+874 $\mathrm{A} / \mathrm{T}$ ) with Hashimoto's Thyroiditis and Graves' disease. Scandinavian Journal of Immunology 64: 438-443.

12. Kung AW, Ma L, Lau KS (1992) The role of interferon-gamma in lymphocytic thyroiditis: its functional and pathological effect on human thyrocytes in culture. Clin Exp Immunol 87: 261-265.

13. Beckett GJ, Arthur JR (2005) Selenium and endocrine systems. J Endocrinol 184: 455-465.

14. Lehmann P, Rank P, Hallfeldt KL, Krebs B, Gärtner R (2006) Dose-related influence of sodium selenite on apoptosis in human thyroid follicles in vitro induced by iodine, EGF, TGF-beta, and $\mathrm{H} 2 \mathrm{O} 2$. Biol Trace Elem Res 112: $119-130$.

15. Tesarik J, Mendoza C, Greco E (2000) The effects of FSH on male germcell survival and differentiation in vitro is mimicked by pentoxifylline but not insulin. Molecular human reproduction 6: 887-881.

16. Toulis KA, Anastasilakis AD, Tzellos TG, Goulis DG, Kouvelas D (2010) Selenium supplementation in the treatment of Hashimoto's thyroiditis: a systematic review and a meta-analysis. Thyroid 20: 1163-1173.

17. Gartner R, Gasnier BCH, Dietrich JW (2002) Selenium supplementation in patients with autoimmune thyroiditis decreases thyroid peroxidase antibodies concentrations. Journal of Clinical Endocrinology and Metabolism 87: 1687-1691.

18. Duntas LH, Mantzou E, Koutras DA (2003) Effects of a six month treatment with selenomethionine in patients with autoimmune thyroiditis. Eur J Endocrinol 148: 389-393.

19. Turker O, Kumanlioglu K, Karapolat I, Dogan I (2006) Selenium treatment in autoimmune thyroiditis: 9-month follow-up with variable doses. J Endocrinol 190: 151-156.

20. Drutel A, Archambeaud F, Caron P (2013) Selenium and the thyroid gland: more good news for clinicians. Clin Endocrinol (Oxf) 78: 155-164. 
21. Azimi A, Ziaee SM, Farhadi P, Sagheb MM (2015) Hypothesis: Pentoxifylline explores new horizons in treatment of preeclampsia. Med Hypotheses 85: 468-474.

22. Bhat VB, Madyastha KM (2001) Antioxidant and radical scavenging properties of 8-oxo derivatives of xanthine drugs pentoxifylline and lisofylline. Biochem Biophys Res Commun 288: 1212-1217.

23. Salhiyyah K, Senanayake E, Abdel-Hadi M, Booth A, Michaels JA (2012) Pentoxifylline for intermittent claudication. Cochrane Database Syst Rev 1: CD005262.

24. Chen YM, Lin SL, Chiang WC, Wu KD, Tsai TJ (2006) Pentoxifylline ameliorates proteinuria through suppression of renal monocyte chemoattractant protein-1 in patients with proteinuric primary glomerular diseases. Kidney Int 69: 1410-5.

25. [No authors listed] (1996) European Pentoxifylline Multi-Infarct Dementia Study. Eur Neurol 36: 315-321.

26. Brant WO, Dean RC, Lue TF (2006) Treatment of Peyronie's disease with oral pentoxifylline. Nat Clin Pract Urol 3: 111-115.

27. Beegle SH, Barba K, Gobunsuy R, Judson MA (2013) Current and emerging pharmacological treatments for sarcoidosis: a review. Drug Des Devel Ther 7: 325-338.

28. Laczy B, Cseh J, Mohas M, Marko L, Tamasko M, et al. (2009) Effects of pentoxifylline and pentosanpolysulphate combination therapy on diabetic neuropathy in type 2 diabetes mellitus. Acta Diabetol 46: 105-11.

29. Sherer JT, Glover PH (2000) Pentoxifylline for sickle-cell disease. Ann Pharmacother 34: 1070-1074.

30. Akriviadis E, Botla R, Briggs W, Han S, Reynolds T, et al. (2000) Pentoxifylline improves short-term survival in severe acute alcoholic hepatitis: a double-blind, placebo-controlled trial. Gastroenterology 119: 1637-1648.

31. Li W, Zheng L, Sheng C, Cheng X, Qing L, et al. (2011) Systematic review on the treatment of pentoxifylline in patients with non-alcoholic fatty liver disease. Lipids Health Dis 10: 49

32. Alborzi S, Ghotbi S, Parsanezhad ME, Dehbashi S, Alborzi S, et al. (2007) Pentoxifylline therapy after laparoscopic surgery for different stages of endometriosis: a prospective, doubleblind, randomized, placebocontrolled study. J Minim Invasive Gynecol 14: 54- 8.

33. Okunieff P, Augustine E, Hicks JE, Cornelison TL, Altemus RM, et al. (2004) Pentoxifylline in the treatment of radiation-induced fibrosis. J Clin Oncol 22: 2207-2213.

34. Delanian S, Porcher R, Rudant J, Lefaix JL (2005) Kinetics of response to long-term treatment combining pentoxifylline and tocopherol in patients with superficial radiation-induced fibrosis. J Clin Oncol 23: 8570-8579.

35. Bienvenu J, Doche C (1995) Production of Proinflammatory Cytokines and Cytokines involved in TH1/TH2 Balance Is Modulated by Pentoxifylline. Journal of Cardiovascular Pharmacology 25: S80-S84.

36. Del Prete GF, Tiri A, Mariotti S, Pinchera A, Ricci M, et al. (1987) Enhanced production of gamma-interferon by thyroid-derived $\mathrm{T}$ cell clones from patients with Hashimoto's thyroiditis. Clin Exp Immunol 69: 323-331.

37. De Prete GF, Tiri A, De Carli M, Mariotti S, Pinchera I, et al. (1989) High potential to TNFa production of thyroid infiltrating $\mathrm{T}$ lymphocytes in Hashimoto's thyroiditis: a peculiar feature of destructive thyroid autoimmunity. Autoimmunity 4: 267-72.

38. Kennedy RL, Jones TH, Davies R, Justice SK, Leusine NR (1992) Release of IL- 6 by human thyroid epithelial cells immortalised by Simian virus 40 DNA transfection. J Endocrinol 133: 4771-6.

39. Diamant M, Kayser L, Rasmussen AK, Bech K, Feldt-Rassmussen U (1991) Interleukin-6 production by thyroid epithelial cells. Enhancement by interleukin-1. Autoimmunity 11:21-26.

40. Ji Q, Zhang L, Jia H, Xu J (2004) Pentoxifylline inhibits endotoxininduced NF-kappa $\mathrm{B}$ activation and associated production of proinflammatory cytokines. Ann Clin Lab Sci 34: 427-436.

41. Benbernou N, Esnault S, Shin HCK, Fekkar H, Guenounou M (1997) Differential regulation of IFN-y, IL-10 and inducible nitric oxide synthase in human T cells by cyclic AMP-dependent signal transduction pathway. Immunology 91: 361-368.

42. Batteux F, Trebeden H, Charreire J, Chiocchia G (1999)Curative treatment of experimental autoimmune thyroiditis by in vivo administration of plasmid DNA coding for interleukin-10. Eur J Immunol 29: 958-963.

43. de Waal Malefyt R, Abrams J, Bennett B, Figdor CG, de Vries JE (1991) Interleukin 10(IL-10) inhibits cytokine synthesis by human monocytes: an autoregulatory role of IL-10 produced by monocytes. J Exp Med 174: 1209-1220.

44. Fiorentino DF, Zlotnik A, Mosmann TR, Howard M, O’Garra AO (1991) IL-10 inhibits cytokine production by activated macrophages. J Immunol 147: 3815-22.

45. Bogdan C, Paik J, Vodovotz Y, Nathan C (1992) Contrasting mechanisms for suppression of macrophage cytokine release by transforming growth factor-beta and interleukin-10. J Biol Chem 267: 23301-23308.

46. Aebischer I, Stadler BM (1996) TH1-TH2 cells in allergic responses: at the limits of a concept. Adv Immunol 61: 341-403.

47. Kawakami Y, Kuzuya N, Watanabe T, Uchiyama Y, Yamashita K (1990) Induction of experimental thyroiditis in mice by recombinant interferon gamma administration. Acta Endocrinol (Copenh) 122: 41-48.

48. Todd I, Pujol-Borrell R, Hammond LJ, McNally JM, Feldmann M, et al. (1987) Enhancement of thyrocyte HLA class II expression by thyroid stimulating hormone. Clin Exp Immunol 69: 524-531.

49. Bottazzo GF, Todd I, Mirakian R, Belfiore A, Pujol-Borrell R (1986) Organ-specific autoimmunity: a 1986 overview. Immunol Rev 94: 137-169.

50. Zipris D, Greiner DL, Malkani S, Whalen B, Mordes JP, et al. (1996) Cytokine gene expression in islets and thyroids of BB rats. IFN-gamma and IL-12p40 mRNA increase with age in both diabetic and insulintreated nondiabetic BB rats. J Immunol 156: 1315-1321.

51. Samardzic T, Jankovic V, Stosic-Grujicic S, Popadic D, Trajkovic V (2001) Pentoxifylline inhibits the synthesis and IFN-gamma-inducing activity of IL-18. Clin Exp Immunol 124: 274-281.

52. Li D, Cai W, Gu R, Zhang Y, Zhang H, et al. (2013) Th17 cell plays a role in the pathogenesis of Hashimoto's thyroiditis in patients. Clin Immunol 149: 411-420.

53. Wilson NJ, Boniface K, Chan JR, McKenzie BS, Blumenschein WM, et al. (2007) Development, cytokine profile and function of human interleukin 17-producing helper T cells. Nat Immunol 8: 950-957.

54. Ji Y, Zhang W (2010) Th17 cells: positive or negative role in tumor? Cancer Immunol Immunother 59: 979-987.

55. Annunziato F, Romagnani S (2009) Do studies in humans better depict Th17 cells? Blood 114: 2213-2219.

56. Lee YK, Turner H, Maynard CL, Oliver JR, Chen D, et al. (2009) Late developmental plasticity in the Thelper 17 lineage. Immunity 30: 92-107.

57. Annunziato F, Cosmi L, Santarlasci V, Maggi L, Liotta F, et al. (2007) Phenotypic and functional features of human Th17 cells. J Exp Med 204: 1849-1861.

58. Bonecchi R, Bianchi G, Bordignon PP, D'Ambrosio D, Lang R, et al. (1998) Differential expression of chemokine receptors and chemotactic responsiveness of type $1 \mathrm{~T}$ helper cells (Th1s) and Th2s. J Exp Med 187: 129-134.

59. Moller DR, Wysocka M, Greenlee BM, Ma X, Wahl L, et al. (1997) Inhibition of human interleukin-12 production by pentoxifylline. Immunology 91: 197-203.

60. Mándi Y, Farkas G, Ocsovszky I, Nagy Z (1995) Inhibition of tumor necrosis factor production and ICAM-1 expression by pentoxifylline: beneficial effects in sepsis syndrome. Res Exp Med (Berl) 195: 297-307.

61. Neuner P, Klosner G, Pourmojib M, Knobler R, Schwarz T (1997) Pentoxifylline in vivo and in vitro down-regulates the expression of the intercellular adhesion molecule-1 in monocytes. Immunology 90: 435-439. 
Citation: Azimi A (2016) Pentoxifylline Explores New Horizons in Treatment of Hashimoto Thyroiditis. Biol Med (Aligarh) 8: 293. doi: 10.4172/0974-8369.1000293

Page 6 of 6

62. Stefanovich V (1974) Concerning specificity of the influence of pentoxifylline on various cyclic AMP phosphodiesterases. Res Commun Chem Pathol Pharmacol 8: 673-680.

63. Akio Yoshida, Toshiaki Adachi, Toshiyuki Noguchi, Keita Urabe, Sumiko Onoyama, et al. (1985) Echographic Findings and Histological Feature of the Thyroid:A Reverse Relationship Between the Level ofEcho-Amplitude and Lymphocytic Infiltration. Endocrinol Japon 32: 681-690.

64. Border WA, Ruoslahti E (1992) Transforming growth factor-beta in disease: the dark side of tissue repair. J Clin Invest 90: 1-7.

65. Cheng-Chung F, Chung-Jen Y, Yung-Ming C, Ren-Shi Shyu, Tun-Jun T, et al. (2000) Pentoxifylline inhibits human peritoneal mesothelial cell growth and collagen synthesis: Effects on TGF-b. Kidney International 57: 2626-2633.

66. Offner FA, Feichtinger H, Stadlmann S, Obrist P, Marth C, et al. (1996) Transforming growth factor-beta synthesis by human peritoneal mesothelial cells. Induction by interleukin-1. Am J Pathol 148: 1679-1688.

67. Deshpande V, Huck A, Ooi E, Stone JH, Faquin WC, et al. (2012) Fibrosing variant of Hashimoto thyroiditis is an IgG4 related disease. J Clin Pathol 65: 725-8.

68. Caraccio N, Natali A, Sironi A, Baldi S, Frascerra S, et al. (2005) Muscle metabolism and exercise tolerance in subclinical hypothyroidism: a controlled trial of levothyroxine. J Clin Endocrinol Metab 90: 4057-4062.
69. Rosenbaum RL, Barzel US (1982) Levothyroxine replacement dose for primary hypothyroidism decreases with age. Ann Intern Med 96: 53-55.

70. Turner MR, Camacho X, Fischer HD, Austin PC, Anderson GM, et al. (2011) Levothyroxine dose and risk of fractures in older adults: nested case-control study. BMJ 342: d2238.

71. Mooradian AD (1995) Normal age-related changes in thyroid hormone economy. Clin Geriatr Med 11: 159-169.

72. Sawin CT, Geller A, Hershman JM, Castelli W, Bacharach P (1989) The aging thyroid. The use of thyroid hormone in older persons. JAMA 261: 2653-2655.

73. Dong BJ, Gambertoglio JG, Greenspan FS, Hauck WW (1997) Bioequivalence of Levothyroxine Preparations for Treatment of Hypothyroidism-Reply. JAMA 277: 1199-1200.

74. Safarinejad MR, Asgari MA, Hosseini SY, Dadkhah F (2010) A doubleblind placebo-controlled study of the efficacy and safety of pentoxifylline in early chronic Peyronie's disease. BJU Int 106: 240-248.

75. Meininger V, Asselain B, Guillet P, Leigh PN, Ludolph A, et al. (2006) Pentoxifylline European Group. Pentoxifylline in ALS: a double-blind, randomized, multicenter, placebo-controlled trial. Neurology 66: 88-92. 